\title{
Multiple sclerosis and occupational exposure to chemicals: a co-twin control study of a nationwide series of twins
}

\author{
J JUNTUNEN, ${ }^{1}$ E KINNUNEN, ${ }^{1}$ M ANTTI-POIKA, ${ }^{2}$ M KOSKENVUO ${ }^{3}$
}

From the Departments of Clinical Neurosciences ${ }^{1}$ and Occupational Medicine, ${ }^{2}$ Institute of Occupational Health, SF-00250 Helsinki, and Department of Public Health, ${ }^{3}$ University of Helsinki, SF-00290 Helsinki, Finland

\begin{abstract}
From the Finnish Twin Cohort ( $n=27100$ pairs with known zygosity) all cases of diagnosed multiple sclerosis (MS) were reviewed and those with clinically verified MS were invited for further examinations at the Institute of Occupational Health, Helsinki, with their co-twins. Twenty one cases (19 pairs, of which 17 were discordant) fulfilled the strict criteria of MS. Detailed occupational history showed exposure to a mixture of solvents in six subjects, to lead in one, and to trichloroethylene in one. Of these seven, two monozygotic twins had MS whereas the other five cases were healthy co-twins. These results do not support a causal association between occupational exposure to chemicals and the aetiopathogenesis of MS.
\end{abstract}

Multiple sclerosis (MS), as with many other neurological diseases of unknown aetiology, has often been associated with some environmental factor. Indeed, the geographical distribution of this disease strongly suggests the important role of environmental factors in its aetiopathogenesis. ${ }^{1-4}$ Attention has been focused on the contribution of occupational factors, notably on exposure to metals and solvents in the manifestation of multiple sclerosis. ${ }^{5-7}$ Owing to the relatively low occurrence of MS in the general population and the difficulties in estimating exposure on the basis of mere occupation, epidemiological studies have yielded conflicting results. Since the role of occupational exposure to chemicals in the aetiopathogenesis of MS seems to be an issue of continuous controversy, we decided to test it by a co-twin control study in a nationwide Finnish Twin Cohort. ${ }^{8}$

\section{Patients and methods}

\section{SOURCE OF CASES OF MS}

The Finnish Twin Cohort consists of all Finnish adult same sexed twin pairs. There were 27100 pairs with known zygosity (10 177 monozygotic and 16923 dizygotic pairs). Zygosity determination was based on self reported similarity at school age and validated using 11 blood markers in a subsample. 9 The data on this cohort were linked with the Hospital Discharge

Accepted 6 June 1988
Registry (up to the end of 1985) using the unique identification number assigned to each Finnish citizen. Since 1972, a computer file has been maintained on patients treated in the Finnish hospitals. All patients with a diagnosis of MS were coded according to the International Statistical Classification of Diseases, Injuries and Causes of Death (ICD). Additional information was obtained from the registers of the Social Security Institution (up to the end of 1985) concerning the degree of work disability and eligibility for free medication for certain chronic diseases, including MS, under the Sickness Insurance Act. All cases diagnosed as having MS until the end of 1985 were picked up. The case records were reviewed by a neurologist (EK) and altogether 23 met the criteria of clinically definite MS according to the Schumacher Committee. ${ }^{10}$ Of these pairs, two were unable to participate because of the death of the co-twin; two pairs refused. Altogether 19 pairs were subjected to detailed investigations at the Institute of Occupational Health, Helsinki.

\section{CLINICAL EXAMINATION OF THE PATIENTS}

At the Institute of Occupational Health each patient and co-twin was examined independently by two experienced neurologists ( $\mathrm{JJ}$ and EK) and a standardised clinical evaluation form was completed in each case. ${ }^{3}$ A comprehensive battery of tests performed on each case included various tests of quantitative neurology, magnetic resonance imaging of the brain, and extensive biochemical and immunological 
Data about age, sex, zygosity, duration of MS, exposure, and exposure category of 19 twin pairs

\begin{tabular}{|c|c|c|c|c|c|c|c|}
\hline Pair & & Age & Sex & Zygosity & $\begin{array}{l}\text { Duration of } \\
M S(y)\end{array}$ & $\begin{array}{l}\text { Occupational } \\
\text { exposure }\end{array}$ & $\begin{array}{l}\text { Exposure } \\
\text { category }\end{array}$ \\
\hline $1 \stackrel{a}{b}$ & $\begin{array}{l}a \\
b\end{array}$ & 66 & $\mathbf{M}$ & $\mathbf{M Z}$ & $\begin{array}{l}28 \\
\text { (probable) }\end{array}$ & $\begin{array}{l}0 \\
0\end{array}$ & $\begin{array}{l}0 \\
0\end{array}$ \\
\hline 2 & $\begin{array}{l}\text { a } \\
b\end{array}$ & 49 & $\mathbf{F}$ & $\mathbf{M Z}$ & $\begin{array}{l}25 \\
24\end{array}$ & $\begin{array}{l}0 \\
0\end{array}$ & $\begin{array}{l}0 \\
0 \\
0\end{array}$ \\
\hline 3 & $\begin{array}{l}\text { a } \\
b\end{array}$ & 44 & $\mathbf{F}$ & $\mathbf{D Z}$ & 21 & $\begin{array}{l}\mathbf{0} \\
\mathbf{0}\end{array}$ & $\begin{array}{l}0 \\
0\end{array}$ \\
\hline $4 a$ & a & 47 & $\mathrm{~F}$ & $\mathbf{M Z}$ & $\overline{11}$ & $\begin{array}{l}0 \\
\text { Solvents }\end{array}$ & $\begin{array}{l}0 \\
2\end{array}$ \\
\hline $5 \mathrm{a}$ & a & 39 & $\mathbf{M}$ & $\mathbf{M Z}$ & $\overline{13}$ & Lead* & $\begin{array}{l}2 \\
1 \\
0\end{array}$ \\
\hline $6 \mathrm{a}$ & $\begin{array}{l}\mathbf{a} \\
\mathrm{b}\end{array}$ & 45 & $\mathbf{F}$ & DZ & $\underline{8}$ & $\begin{array}{l}0 \\
0\end{array}$ & $\begin{array}{l}0 \\
0\end{array}$ \\
\hline $7 \mathrm{a}$ & $\begin{array}{l}\text { a } \\
\text { b }\end{array}$ & 50 & $\mathbf{F}$ & $\mathrm{DZ}$ & 23 & $\begin{array}{l}0 \\
0\end{array}$ & $\begin{array}{l}0 \\
0\end{array}$ \\
\hline $8 \stackrel{a}{b}$ & $\begin{array}{l}\mathbf{a} \\
\mathbf{b}\end{array}$ & 42 & $\mathbf{F}$ & $\mathbf{M Z}$ & 24 & $\begin{array}{l}0 \\
\text { Solvents }\end{array}$ & $\begin{array}{l}0 \\
2\end{array}$ \\
\hline $9 \mathrm{a}$ & $\begin{array}{l}\text { a } \\
\text { b }\end{array}$ & 59 & $\mathbf{F}$ & $\mathrm{DZ}$ & 49 & $\begin{array}{l}0 \\
0\end{array}$ & $\begin{array}{l}0 \\
0\end{array}$ \\
\hline $10 \stackrel{a}{b}$ & $\begin{array}{l}\text { a } \\
\text { b }\end{array}$ & 30 & $\mathbf{M}$ & $\mathbf{M Z}$ & 10 & $\begin{array}{l}\text { Solvents* } \\
\text { Solvents }\end{array}$ & 1 \\
\hline $11 \stackrel{a}{b}$ & & 45 & $\mathbf{M}$ & $\mathrm{DZ}$ & 21 & $\begin{array}{l}0 \\
\text { Trichloroethylene }\end{array}$ & 0 \\
\hline $12 \mathrm{a}$ & $\begin{array}{l}\mathbf{a} \\
\mathbf{b}\end{array}$ & 29 & $\mathbf{M}$ & $\mathbf{M Z}$ & 10 & $\begin{array}{l}0 \\
\text { Solvents }\end{array}$ & $\begin{array}{l}0 \\
2\end{array}$ \\
\hline $13 \stackrel{a}{\mathrm{~b}}$ & & 34 & $\mathbf{F}$ & $\mathrm{DZ}$ & 17 & $\begin{array}{l}0 \\
0\end{array}$ & $\begin{array}{l}0 \\
0\end{array}$ \\
\hline $14 \mathrm{a}$ & $\begin{array}{l}\text { a } \\
\text { b }\end{array}$ & 29 & $F$ & DZ & 13 & $\begin{array}{l}0 \\
0\end{array}$ & $\begin{array}{l}0 \\
0\end{array}$ \\
\hline $15 \mathrm{a}$ & a & 44 & $\mathbf{F}$ & $\mathbf{M Z}$ & $\underline{2}$ & $\begin{array}{l}0 \\
0 \\
0\end{array}$ & $\begin{array}{l}0 \\
0 \\
0\end{array}$ \\
\hline $16 \stackrel{a}{b}$ & a & 40 & $\mathbf{F}$ & $\mathbf{M Z}$ & $\underline{13}$ & $\begin{array}{l}0 \\
0\end{array}$ & $\begin{array}{l}0 \\
0\end{array}$ \\
\hline $17 \stackrel{a}{b}$ & a & 27 & $\mathbf{F}$ & DZ & $\underline{9}$ & $\begin{array}{l}0 \\
\text { Solvents }\end{array}$ & 0 \\
\hline $18 \stackrel{a}{b}$ & a & 59 & $\mathbf{F}$ & $\mathbf{M Z}$ & $\underline{30}$ & $\begin{array}{l}0 \\
0\end{array}$ & $\begin{array}{l}0 \\
0\end{array}$ \\
\hline $19 \mathrm{a}$ & $\begin{array}{l}\mathbf{a} \\
\mathbf{b}\end{array}$ & 41 & $\mathbf{F}$ & DZ & $\underline{24}$ & $\begin{array}{l}0 \\
0\end{array}$ & $\begin{array}{l}0 \\
0\end{array}$ \\
\hline
\end{tabular}

laboratory tests. Based on these examinations, definite MS could be ascertained in 20 cases, 11 monozygotic and nine dizygotic twins. In addition, one monozygotic twin had probable MS. Detailed clinical findings of the first 13 pairs have been reported separately. ${ }^{\prime \prime}$

\section{OCCUPATIONAL HISTORY AND ESTIMATION OF EXPOSURE}

A detailed history of exposures at workplaces as well as at leisure were taken from each subject by a specialist in occupational medicine (MAP). The following specific aspects were registered:

Chemical compounds used

Work tasks with exposure and methods used

Working conditions and description of ventilation

Protective equipment used

Results of biological monitoring (lead exposure)

Possible work related symptoms

Possible work related illnesses of co-workers

Based on these data, estimates were made about the exposure to chemical agents in each individual. Exposure was estimated afterwards without knowing whether the person had MS or not. A rough classi-? fication of the severity of exposure was performed: $0=0$ no exposure whatsoever, $1=$ occasional exposure, and 2 = slight exposure.

\section{Results}

The table shows the data about the 19 pairs $(38$ subjects) included in the final analysis. Two pairs (1.0 and 2) were concordant for MS. No occupational exposure to any chemicals could be established in $30 \mathrm{~N}$ (nine MS cases, 11 healthy co-twins). In eight the occupational history showed exposure to either organic solvents or heavy metals. In all cases the extent of exposure was relatively low and only one (4b) had: been exposed to relatively high levels of solvent 0 mixtures for five years. From the exposed subjects, twoo monozygotic cases had MS, one with borderline lead exposure and one with occasional exposure to a疋 
mixture of solvents. The onset of MS was preceded by 12 years slight exposure to lead in the first case. The second case was occasionally exposed to a mixture of solvents for two years at the time of onset of MS. The remaining six exposed subjects, including the two in exposure category 2, were healthy co-twins. The association of exposure with MS was not statistically significant ( $p>0 \cdot 1, \mathrm{McNemar}$ test) and the relative risk was 0.40 (MS concordant pairs excluded).

\section{Discussion}

Individuals of this study were taken from a nationwide twin panel. The prevalence of MS was 54/100 000 in the twin panel and 52/100 000 in the Finnish population, suggesting a good representativeness. ${ }^{8}$ The geographical distribution of MS in Finland ${ }^{12}$ as in many other countries ${ }^{1314}$ does not show any clustering of this disease in industrialised regions. Nevertheless, case reports and other studies associating MS with exposure to various neurotoxic and other chemicals are frequently published. ${ }^{15}$ Lauer and Firnhaber analysed the patterns of the patients' occupations during adolescence and onset of MS in West Germany and found that male patients were more frequently occupied in metal processing and electrical trades than expected. ${ }^{6}$ At the onset of MS, more female patients than expected were working in commerce and administration, whereas male patients did not differ from the pattern in the general German population. In another study from the United States no unusual exposures were encountered among cases of MS. $^{4}$ An epidemiological survey from Florence suggested an increased risk of MS among shoe and leather workers and the authors discuss the possible role of solvents. Lead has been associated with MS in some studies ${ }^{16}$ whereas some others have failed to show this association. ${ }^{17} \mathrm{~A}$ recent study showed increased incidence of MS among workers in zinc related manufacturing plants, but a subsequent case referent survey failed to confirm an association between exposure and the disease. ${ }^{7}$ In another study a decrease in erythrocyte zinc levels was shown during clinical exacerbation of MS. ${ }^{\prime}$ A recent case-referent study from Sweden reports association between MS, solvent exposure, and pet contacts. ${ }^{18}$

Most of these studies have inherent problems that make it difficult to draw causal associations between the disease and exposure. Firstly, representativeness of the diseased populations and their referents is not always good, due mostly to small group sizes. Secondly, the criteria of MS vary greatly and many symptoms and signs resembling those of MS may have been inadvertently included into cases. Thirdly, it is difficult to obtain adequate data about exposure without expertise in occupational medicine and occupational hygiene. In our study many of these problems have been overcome: our sample was obtained from a nationwide cohort and is thus representative of the
Finnish population. We confirmed the diagnosis of MS by new techniques and performed a detailed estimation of occupational exposure to chemicals. The discordant pair study design allowed for an optimal comparison between cases and referents. Information bias, if any, should have operated towards causal association between exposure and the disease. Hence, despite the small number of cases, and low levels of exposure in this study, we feel justified in concluding that our results do not support the contention of causal association between occupational chemical factors and the manifestation of MS.

\section{References}

1 Ho SY, Catalanotto FA, Lisak RP, Dore-Duffy P. Zinc in multiple sclerosis. II. Correlation with disease activity and elevated plasma membrane-bound zinc in erythrocytes from patients with multiple sclerosis. Ann Neurol 1986;20:712-5.

2 Häsänen E, Kinnunen E, Alhonen P. Relationship between the prevalence of multiple sclerosis and some physical and chemical properties of soil. Sci Total Environ 1986;58:263-72.

3 Ingalls TH. Epidemiology, etiology, and prevention of multiple sclerosis. Hypothesis and fact. Am J Forensic Med Pathol 1983;4:55-61.

4 Koch MJ, Reed D, Stern R, et al. Multiple sclerosis: a cluster in a small northwestern United States community. JAMA 1974; 228:1555-7.

5 Amaducci L, Arfaioli C, Inzitari D, Marchi M. Multiple sclerosis among shoe and leather workers: an epidemiologic survey in Florence. Acta Neurol Scand 1982;65:94-103.

6 Lauer K, Firnhaber W. Epidemiological investigations into multiple sclerosis in southern Hesse. III. The possible influence of occupation on the risk of disease. Acta Neurol Scand 1985; 72:397-402.

7 Stein EC, Schiffer RB, Hall J, Young N. Multiple sclerosis and the workplace: report on an industry-based cluster. Neurology 1987;37:1672-7.

8 Kinnunen E, Koskenvuo M, Kaprio J, Aho K. Occurrence of multiple sclerosis in a nation-wide series of twins. Neurology 1987;37:1672-9.

9 Sarna S, Kaprio J, Sistonen P, Koskenvuo M. Diagnosis of twin zygosity by mailed questionnaire. Hum Hered 1978;28:241-54.

10 Schumacher GA, Beebe G, Kibler RF, et al. Problems of experimental trials of therapy in multiple sclerosis: report by the panel on the evaluation of experimental trials of therapy in multiple sclerosis. Ann NY Acad Sci 1965;122:552-68.

11 Kinnunen E, Juntunen J, Ketonen L, et al. Genetic susceptibility to multiple sclerosis. A co-twin study of a nationwide series. Arch Neurol 1988;45:1108-11.

12 Kinnunen E. Multiple sclerosis in Finland: evidence of increasing frequency and uneven geographic distribution. Neurology 1984;34:457-61.

13 Juntunen J. Occupational solvent poisoning: clinical aspects. In: Safety and health aspects of organic solvents. Riihimäki V, Ulfvarson U, eds. Progress in Clinical and Biological Research 1986;220:265-79.

14 Kurtzke JF, Beebe GW, Norman JE. Epidemiology of multiple sclerosis in USA veterans. 1. Race, sex and geographic distribution. Neurology 1979;29:1228-35.

15 Chapman LJ, Peters HA, Matthews CG, Levine RL. Parkinsonism and industrial chemicals. Lancet 1987;i:332-3.

16 Mahaffey K, Damstra T, Piver WT, et al. Lead toxicity. Human health consequences due to lead exposure from automobile emissions. Research Triangle Park, North Carolina: US Department of Health, Education and Welfare, 1976:185-99.

17 Westerman MP, Bruteman M, Pfitzer E. Lead poisoning and multiple sclerosis. Arch Environ Health 1974;29:355-6.

18 Flodin U, Söderfeldt B, Noorlind-Bruge H, Fredriksson M, Axelson O. Multiple sclerosis, solvents and pets. Arch Neurol 1988;45:620-3. 